\title{
CARACTERIZAÇÃO DE COROAS IMPORTADA E NACIONAL DE ALUMÍNIO FUNDIDO
}

\author{
Camila Alves de Lima Gonçalves \\ Carolina Marques de Paula \\ Gisele Szilágyi
}

Universidade Presbiteriana Mackenzie (UPM)

\begin{abstract}
RESUMO
Entre as ligas usadas na indústria automotiva, as de alumínio ganham destaque por sua leveza, boa resistência à corrosão, alta ductilidade e ótimo desempenho ambiental. Posto isso, o objetivo deste trabalho foi estudar os diferentes comportamentos de desgaste de coroas em ligas de alumínio de origens nacional e importada, utilizadas em carros de kart. Durante as etapas experimentais, as amostras foram caracterizadas por dureza Brinell e microdureza Vickers, análise microestrutural por microscopia óptica (MO) e por microscopia eletrônica de varredura (MEV), e análise de composição química por espectroscopia por dispersão de energia de raios X (EDS), fluorescência de raios $\mathrm{X}$ e absorção atômica. As amostras da coroa importada apresentaram dureza superior às amostras da coroa nacional, alto teor de zinco e microestrutura formada por grãos de aspecto deformado/partículas de segundas fases alinhadas. As amostras da coroa nacional apresentaram teores inferiores de elementos de liga, menor dureza quando comparada à coroa importada e estrutura de grãos que pode ser associada à condição fundida.
\end{abstract}

Palavras-chave: Coroas de liga de alumínio. Kart. Estrutura de grãos. Dureza. Composição química. 


\section{INTRODUÇÃO}

A conjugação de propriedades oferecidas pelas ligas de alumínio, como alta relação resistência/peso, fluidez, elevada ductilidade e resistência à corrosão, tornam esses materiais cada vez mais atrativos para o setor de transportes. Segundo Wongtschowski (2016), atualmente, as principais aplicaçôes no Brasil estão em blocos de motor e outras peças fundidas, como rodas. Além de suas excelentes propriedades, as ligas de alumínio apresentam alto desempenho ambiental, não só por sua facilidade de reciclagem, mas também por promoverem redução na emissão de dióxido de carbono $\left(\mathrm{CO}_{2}\right)$ - a diminuição de massa dos carros é um fator que contribui para a redução de emissôes veiculares.

O consumo de alumínio no setor automobilístico tem crescido exponencialmente nos últimos anos devido à leveza desse material em comparação a do ferro e a do aço, materiais quase onipresentes entre as autopeças. Segundo estudos realizados nos Estados Unidos (ABAL, 2021a), o consumo médio de alumínio nos veículos estadunidenses em 2012 era de $156 \mathrm{~kg}$; e, até 2025, a previsão é que esse consumo seja de $250 \mathrm{~kg}$. Nos transportes, a alta relação entre resistência mecânica/densidade das ligas de alumínio é extremamente vantajosa, uma vez que incorre em menor consumo de combustível e redução na emissão de poluentes. Nesse mesmo setor, a resistência à corrosão das ligas de alumínio contribui para uma ampliação da vida útil das carrocerias de caminhóes. Frotas de caminhóes que fazem uso intensivo de alumínio rodam, em média, 15 anos sem necessidade de manutenção drástica, contra oito anos se utilizados outros materiais (ABAL, 2021b).

O alumínio comercialmente puro não é amplamente utilizado, pois apresenta uma resistência mecânica muito baixa. Com a adição de outros metais (elementos de liga), como silício, cobre, manganês, magnésio, cromo, zinco, ferro etc., atinge-se o principal objetivo das ligas de alumínio, que é aumentar a resistência mecânica sem detrimento de outras propriedades. Dessa forma, novas ligas têm sido desenvolvidas, cada uma com uma combinação apropriada de propriedades adequadas a uma aplicação específica. Descrever a função de cada elemento de liga é difícil, pois ela modifica-se com o teor do elemento adicionado e pela interaçáo com outros elementos.

Nesse contexto, e considerando a diversidade de ligas de alumínio, é especialmente importante a correta seleção de materiais, bem como de processos empregados a eles. Segundo Callister Jr. (2012), as causas mais comuns que resultam em falhas são a má seleção de materiais, processamento inadequado, projeto incompleto (em que não se leva em conta as condiçôes em que os materiais estarão submetidos) e a falta de manutenção. 
O conhecimento das falhas é uma ferramenta essencial para compreender o que aconteceu com o material. Analisar as causas disso pode ser o diagnóstico para evitar outras falhas e defeitos mais complexos na peça. Segundo Affonso (2002, p. 31), "a análise de uma falha nada mais é que o enquadramento da imagem da falha no conjunto de imagens conhecidas, para que seja possível uma identificação".

Os objetos de estudo deste trabalho são coroas de transmissão por corrente, fabricadas em ligas de alumínio e utilizadas em carros de kart. Essas coroas têm como função transmitir e multiplicar torque de um eixo a outro por meio de uma corrente. Comparada a uma engrenagem, a coroa destaca-se devido à liberdade em relação à distância entre os eixos, permitindo ajustar somente o número de elos da corrente, e não o tamanho da coroa motriz (pinháo) e/ou da coroa movida.

Assim, é feito um estudo comparativo entre coroas de ligas de alumínio, uma de origem nacional e outra importada, que apresentaram comportamentos diferentes quanto ao desgaste.

\section{METODOLOGIA}

Para a etapa experimental, foi desenvolvida uma metodologia de análise focada em identificar as causas para os diferentes comportamentos entre as coroas. Os materiais de estudo foram duas coroas de ligas de alumínio, sendo uma importada e a outra nacional, conforme apresentado na Figura 1:

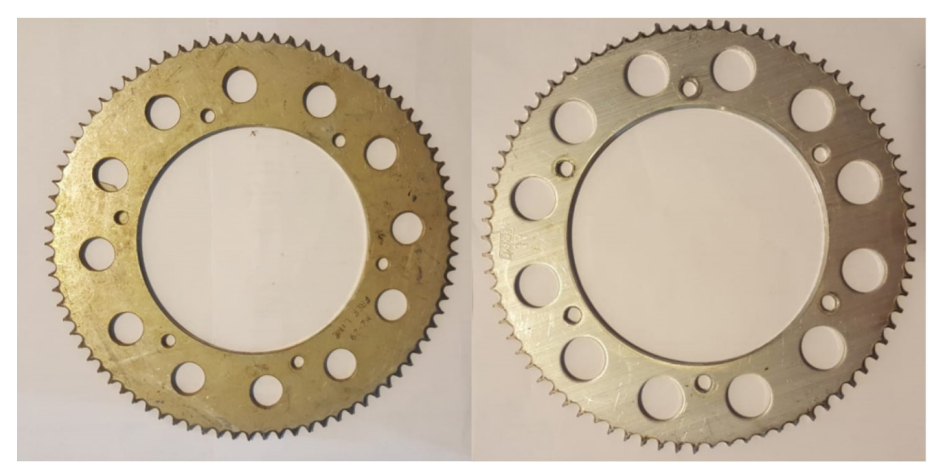

Figura 1 Coroa de alumínio importada (à esquerda) e coroa de alumínio nacional (à direita).

Fonte: Acervo pessoal das autoras (2018). 
A coroa de alumínio nacional possui diâmetro externo de 196 mm, diâmetro interno de $116 \mathrm{~mm}$ e espessura de $4 \mathrm{~mm}$. A coroa de alumínio importada possui diâmetro externo de $208 \mathrm{~mm}$, diâmetro interno de $116 \mathrm{~mm}$ e espessura de $4 \mathrm{~mm}$. As coroas foram cortadas e as amostras embutidas em baquelite, de maneira a se visualizar a seção transversal. As amostras são de três regióes, denominadas 1, 2 e 3, selecionadas de forma a garantir cobertura de análise em toda a seção, conforme disposto na Figura 2.

Para a preparação metalográfica das amostras, foi utilizado o método padrão de lixamento e polimento. Inicialmente, foram usadas lixas de carbeto de silício de granulometria 120, 220, 320, 400, 600 e 1200 \#. Depois, as amostras foram submetidas a um processo de polimento com pasta de diamante de $3 \mu \mathrm{m}$. O ataque químico foi realizado a frio com o reagente Keller $(10 \mathrm{ml}$ de ácido fluorídrico, $15 \mathrm{ml}$ de ácido clorídrico concentrado, $25 \mathrm{ml}$ de ácido nítrico concentrado e $50 \mathrm{ml}$ de água) durante, aproximadamente, 15 segundos e, posteriormente, por 2 minutos, com objetivo de revelar os contornos de grãos e as partículas de segundas fases contidas na liga.
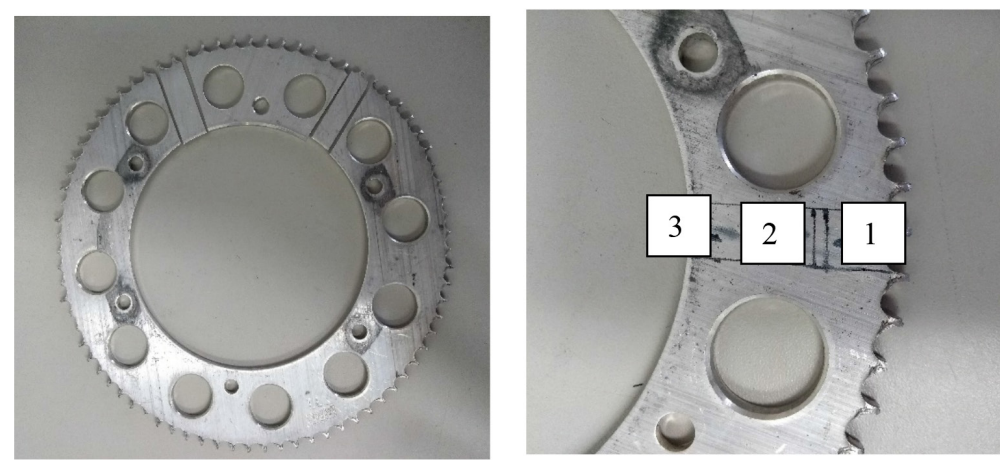

Figura 2 Cortes iniciais (à esquerda) e esquema do corte para avaliação da seção transversal da coroa (à direita).

Fonte: Acervo pessoal das autoras (2018).

Outra técnica utilizada com a finalidade de revelar a estrutura de grãos nas ligas de alumínio foi o ataque químico utilizando new technique" (MOHAMMADTAHERI, 2012). Esse ataque químico consiste em duas etapas: inicialmente, as amostras ficaram pré-condicionadas por 3 minutos em uma solução de $1 \mathrm{~g}$ de cloreto de sódio e $50 \mathrm{ml}$ de ácido fosfórico com concentração de $40 \%$ a $70{ }^{\circ} \mathrm{C}$; em seguida, foram submetidas a uma solução de $100 \mathrm{ml}$ de água, $1 \mathrm{~g}$ de hidróxido de sódio e $4 \mathrm{~g}$ de permanganato de potássio, pelo mesmo tempo. 
Para conhecimento da composição química das amostras, foram utilizadas diferentes técnicas de análise química. Para a técnica de fluorescência de raios X, os corpos-de-prova foram obtidos por usinagem das coroas. Os cavacos dessa usinagem foram utilizados para análise por absorção atômica. As amostras embutidas em baquelite foram utilizadas tanto para análise por microscopia óptica (MO) e microscopia eletrônica de varredura (MEV) quanto para espectroscopia de energia dispersiva (EDS). Já a dureza das coroas foi obtida em duas escalas: Brinell e microdureza Vickers.

\section{RESULTADOS E DISCUSSÃO}

Coroas para kart, uma de fabricação nacional e outra importada, foram cedidas às autoras para a caracterização, de forma a se diagnosticar as causas do desgaste mais acentuado na coroa nacional, quando comparada à importada. As coroas não foram fornecidas com identificação de liga e, do ponto de vista de processamento, a informação de que se dispunha era que as coroas foram obtidas por fundição. Assim, o estudo foi direcionado para caracterizar essas coroas, identificar seus processos produtivos e avaliar como possíveis diferenças em suas composiçôes químicas, microestruturas e durezas pudessem repercutir em desempenhos distintos quanto ao desgaste.

\subsection{Composição química}

Com o intuito de entender se as diferenças no desgaste das coroas estão diretamente relacionadas à composição química, foi empregada, para ambas as coroas, a técnica EDS. Em busca de resultados mais precisos, foram utilizadas, também, as técnicas de absorção atômica e fluorescência de raios X. Os resultados dessas análises são expostos na Tabela 1, para a coroa nacional, e na Tabela 2, para a coroa importada.

Pode-se observar que a coroa importada é mais "carregada" em elementos de liga que a coroa nacional. Elementos como zinco, cobre e manganês são muito importantes nas ligas de alumínio, pois conferem elevada resistência mecânica a esses materiais, o que, por sua vez, pode explicar o melhor desempenho da coroa importada em relação à nacional, no que tange ao desgaste.

Como os resultados obtidos pela técnica de fluorescência de raios $\mathrm{X}$ foram discrepantes em relação aos valores apresentados pela absorção atômica e pelo EDS, foram considerados, para possível classificação das ligas, apenas os resultados obtidos nas 
duas últimas técnicas. Considerando o teor de zinco identificado pela absorção atômica e pelo EDS, a partir da comparação com a norma NBR ISO 209 (ABNT, 2010), a liga da coroa importada pode ser classificada como uma liga trabalhável da série 7000, cujo elemento de liga principal é o zinco. Considerando os teores de zinco e magnésio identificados pela absorção atômica e pelo EDS, a liga pode ser classificada como 7005; se considerados os teores de zinco e cobre identificados pela absorção atômica e pelo EDS, a liga pode ser classificada como 7033. As composiçóes químicas das ligas 7005 e 7033 estão apresentadas nas Tabelas 3 e 4, respectivamente.

\section{TABELA 1}

Composição química da coroa nacional.

\begin{tabular}{cccc} 
Elemento & EDS (\%) & $\begin{array}{c}\text { Absorção atômica } \\
(\%)\end{array}$ & $\begin{array}{c}\text { Fluorescência de raios X } \\
(\%)\end{array}$ \\
Alumínio & 99,45 & Não avaliado** & 95,24 \\
Silício & 0,00 & Não avaliado** & 1,92 \\
Manganês & 0,55 & 0,050 & 1,51 \\
Ferro & Não identificado* & Não avaliado** & 0,70 \\
Cobre & Não identificado* & Não avaliado** & 0,046 \\
Zinco & Não identificado* & 0,010 & 0,00 \\
\hline Magnésio & Não identificado* & 0,42 & 0,21
\end{tabular}

* Esses elementos não foram identificados pela técnica utilizada.

** Esses elementos não foram avaliados por limitação de equipamento.

Fonte: Elaborada pelas autoras. 


\section{TABELA 2}

Composição química da coroa importada.

\begin{tabular}{|c|c|c|c|}
\hline Elemento & EDS (\%) & $\begin{array}{c}\text { Absorção atômica } \\
(\%)\end{array}$ & $\begin{array}{l}\text { Fluorescência de raios } \mathrm{X} \\
\qquad(\%)\end{array}$ \\
\hline Alumínio & 92,71 & Não avaliado** & 79,00 \\
\hline Silício & Não identificado* & Não avaliado** & 1,25 \\
\hline Manganês & Não identificado* & 0,080 & 0,14 \\
\hline Ferro & Não identificado* & Não avaliado** & 0,44 \\
\hline Cobre & 1,23 & Não avaliado** & 3,50 \\
\hline Zinco & 5,35 & 4,70 & 14,60 \\
\hline Magnésio & 0,71 & 1,60 & 0,12 \\
\hline
\end{tabular}

* Esses elementos não foram identificados pela técnica utilizada.

** Esses elementos não foram avaliados por limitação de equipamento.

Fonte: Elaborada pelas autoras.

\section{TABELA 3}

Composição química da liga de alumínio 7005.

\begin{tabular}{ccccccccc}
$\mathrm{Si}$ & $\mathrm{Fe}$ & $\mathrm{Cu}$ & $\mathrm{Mn}$ & $\mathrm{Mg}$ & $\mathrm{Cr}$ & $\mathrm{Ni}$ & $\mathrm{Zn}$ & $\mathrm{Ti}$ \\
0,35 & 0,4 & 0,1 & $0,20-0,7$ & $1,0-1,8$ & $0,06-0,20$ & - & $4,0-5,0$ & $0,01-0,06$ \\
\hline
\end{tabular}

Fonte: ABNT (2010).

\section{TABELA 4}

Composição química da liga de alumínio 7033.

\begin{tabular}{ccccccccc} 
Si & Fe & Cu & Mn & Mg & Cr & Ni & $\mathrm{Zn}$ & Ti \\
\hline 0,15 & 0,3 & $0,70-1,3$ & 0,1 & $1,30-2,20$ & 0,2 & - & $4,60-5,60$ & 0,1 \\
\hline
\end{tabular}

Fonte: ABNT (2010). 
A coroa nacional apresentou teores de elementos de liga muito baixos, não permitindo sua classificação.

\subsection{Microscopia óptica}

A técnica de microscopia óptica foi utilizada para caracterização microestrutural das coroas, como mostram as figuras 3 (coroa nacional) e 4 (coroa importada). O primeiro ataque químico foi realizado por imersão com reagente Keller durante 15 segundos.

As amostras da coroa nacional apresentaram uma distribuição homogênea das partículas de segundas fases, que possuem um tamanho menor em relação às das amostras da coroa importada. $\mathrm{Na}$ análise das amostras da coroa importada, foi observado o alinhamento das partículas de segundas fases. Como o ataque por 15 segundos com reagente Keller não revelou os contornos de grãos, o tempo de contato com a solução foi aumentado para dois minutos. Nesse ataque, ficou clara a diferença entre os processos de fabricação utilizados nas coroas. As figuras 5 e 6 demostram esses resultados.

A partir das microestruturas obtidas das amostras da coroa importada após tempo de ataque de dois minutos com reagente Keller, pôde-se observar características de materiais que sofreram conformação mecânica, como grãos com aspecto encruado ("panquecados") e alinhamento de partículas de segundas fases.

Após dois minutos de ataque com o reagente Keller, as amostras da coroa nacional apresentaram distribuição homogênea das partículas de segundas fases, mas não foi possível observar os contornos de gráos. Com a finalidade de revelar a estrutura de grãos nas amostras da coroa nacional, realizou-se o ataque químico utilizando new technique. Essa técnica possibilitou a observação dos contornos de grãos, como mostra a Figura 7. A forma equiaxial dos grãos revelados pelo ataque é característica de materiais que não se encontram deformados mecanicamente, por exemplo, materiais na condição como fundida. 

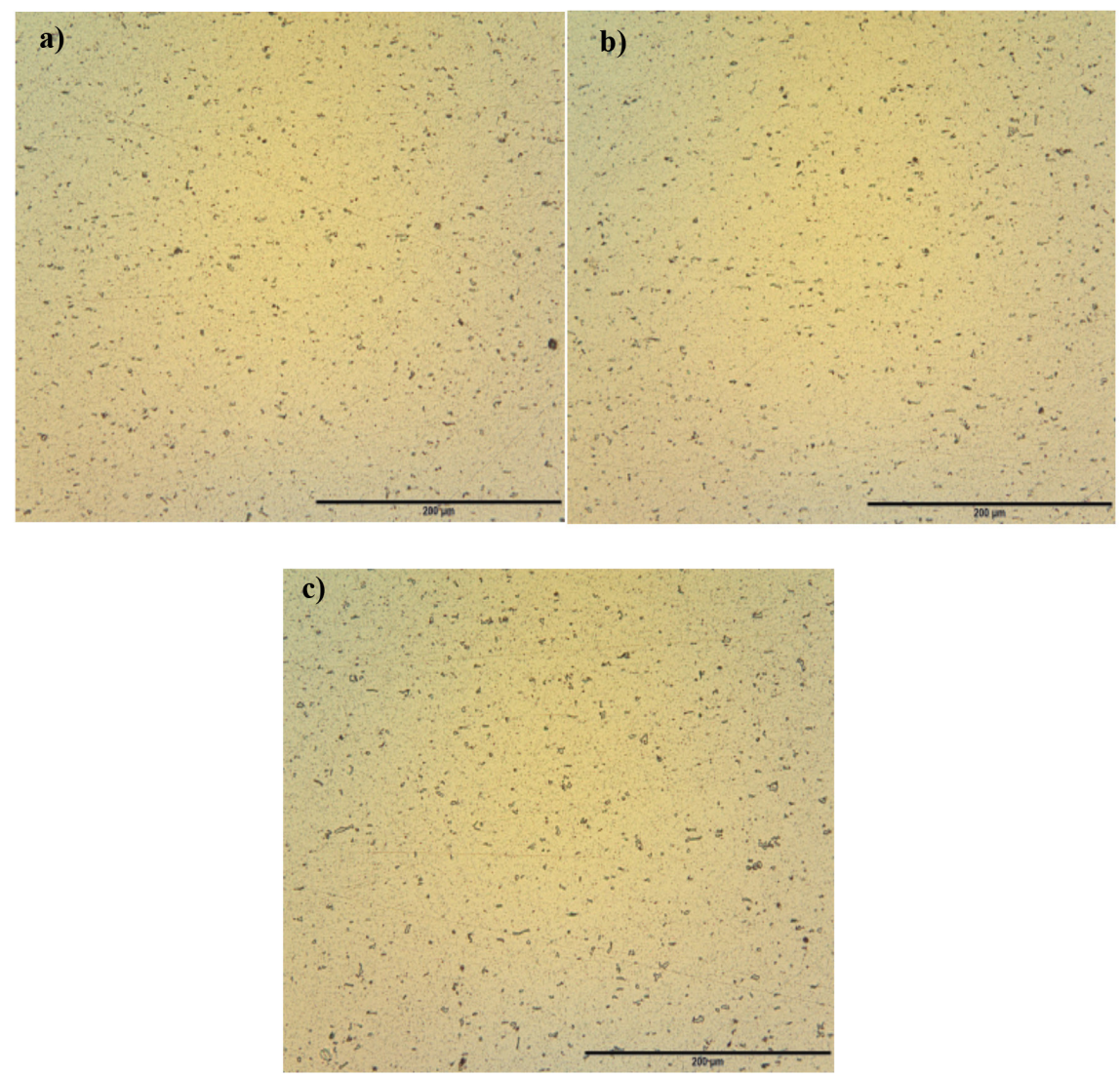

Figura 3 Coroa de alumínio nacional atacada quimicamente por 15 segundos utilizando reagente Keller. a) Amostra 1 observada com aumento de 200 x; b) amostra 2 observada com aumento de $200 \mathrm{x}$; c) amostra 3 observada com aumento de $200 \mathrm{x}$.

Fonte: Elaborada pelas autoras. 

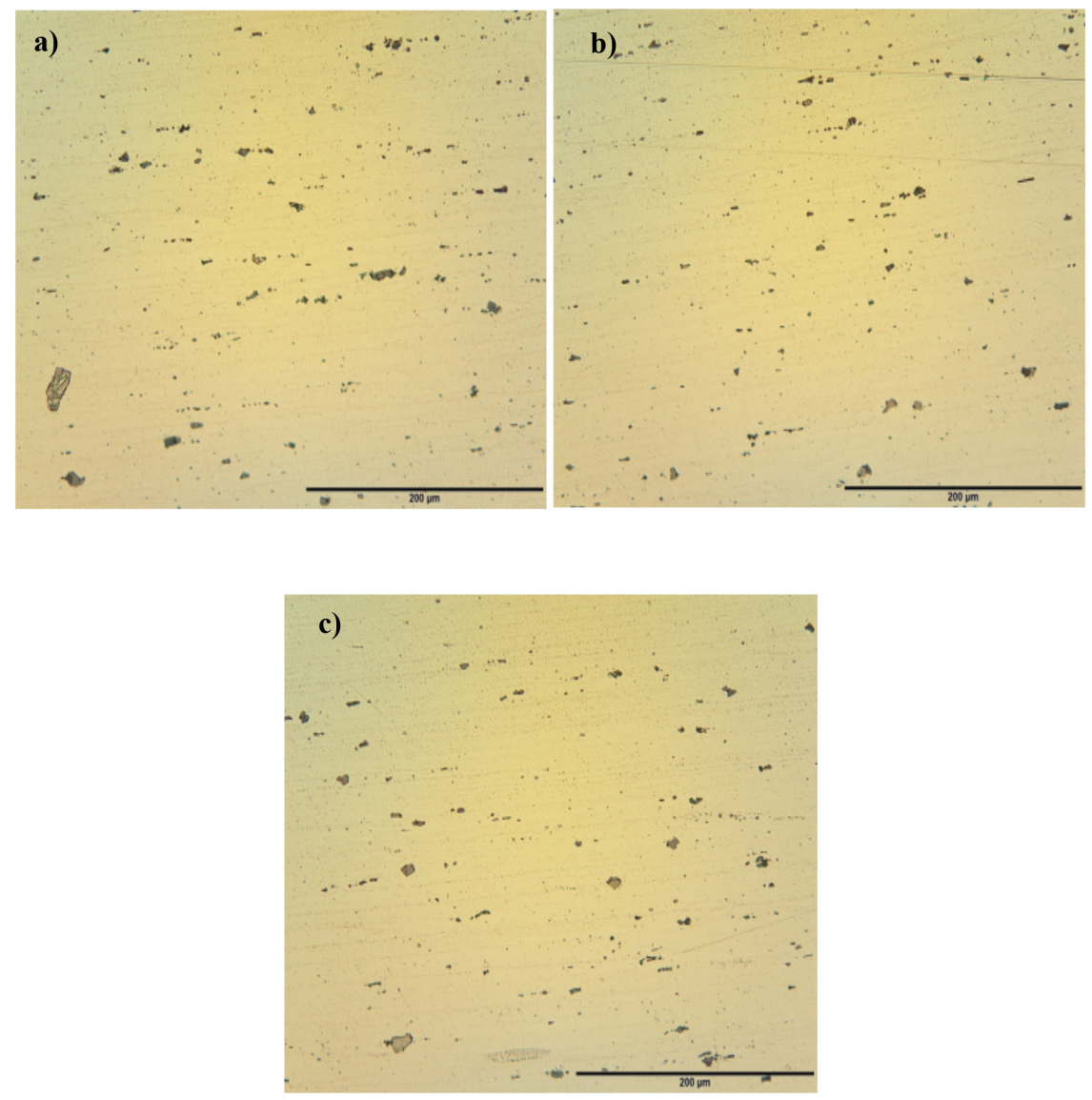

Figura 4 Coroa de alumínio importada atacada quimicamente por 15 segundos utilizando reagente Keller. a) Amostra 1 observada com aumento de 200 x; b) amostra 2 observada com aumento de 200 x; c) amostra 3 observada com aumento de 200 x.

Fonte: Elaborada pelas autoras. 

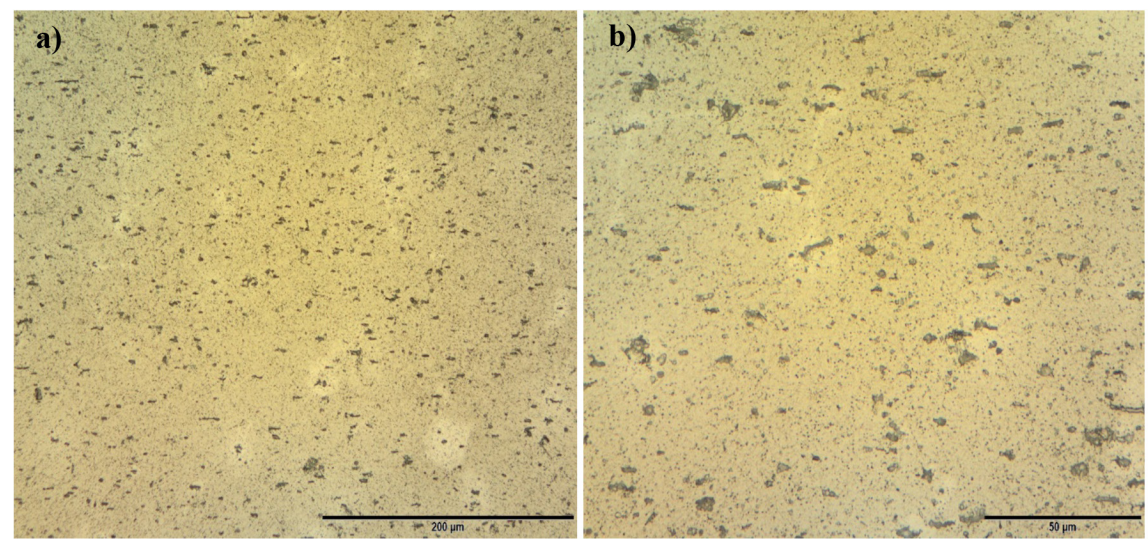

Figura 5 Coroa de alumínio nacional atacada quimicamente por 2 minutos utilizando o reagente Keller. a) Amostra 1 observada com aumento de 200 x; b) amostra 1 com mesmo ataque químico observada com aumento de $500 \mathrm{x}$.

Fonte: Elaborada pelas autoras.
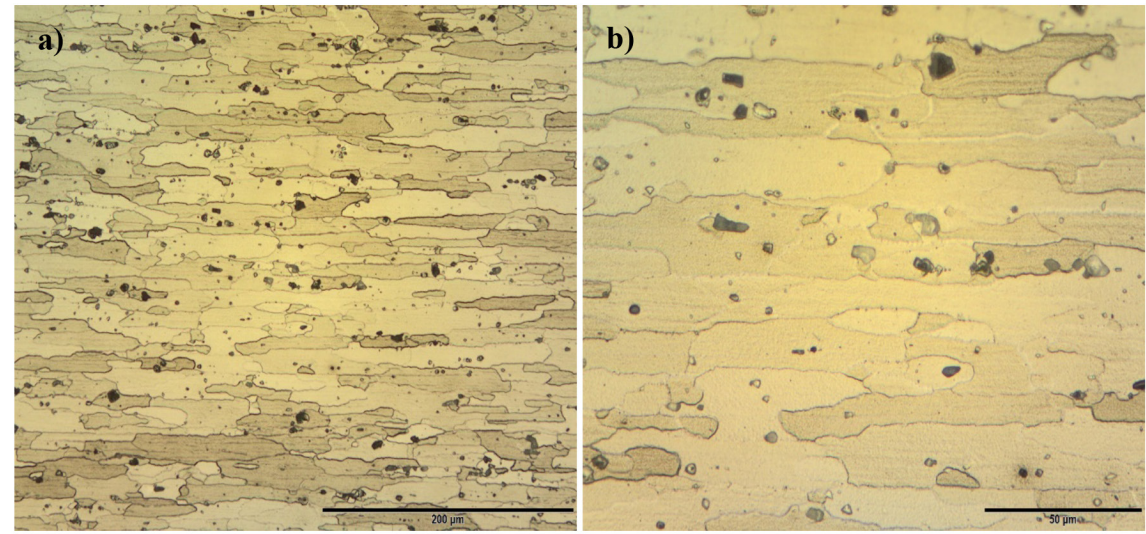

Figura 6 Coroa de alumínio importada atacada quimicamente por 2 minutos utilizando o reagente Keller. a) Amostra 1 observada com aumento de 200 x.; b) amostra 1 com mesmo ataque químico observada com aumento de $500 \mathrm{x}$.

Fonte: Elaborada pelas autoras. 

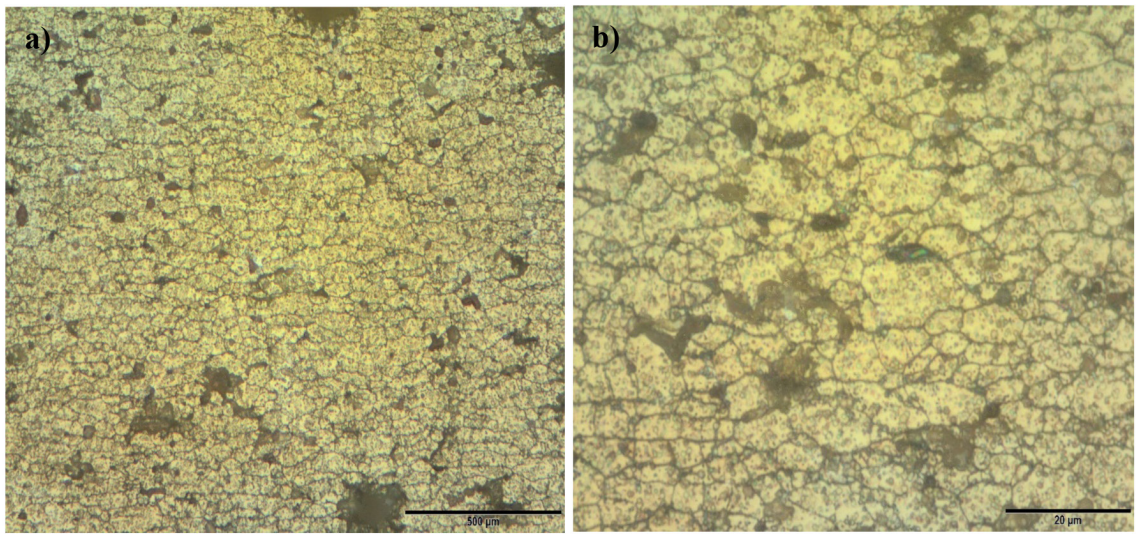

Figura 7 Coroa de alumínio nacional atacada utilizando ataque químico new technique. a) Amostra 1 observada com aumento de 500 x; b) amostra 1 com mesmo ataque químico observada com aumento de $1000 \mathrm{x}$.

Fonte: Elaborada pelas autoras.

\subsection{Microscopia eletrônica de varredura (MEV)}

Com a MEV foi possível confirmar as diferenças entre as coroas previamente reveladas pela microscopia óptica no que se refere às partículas de segundas fases. A Figura 8 mostra as imagens obtidas na MEV: 

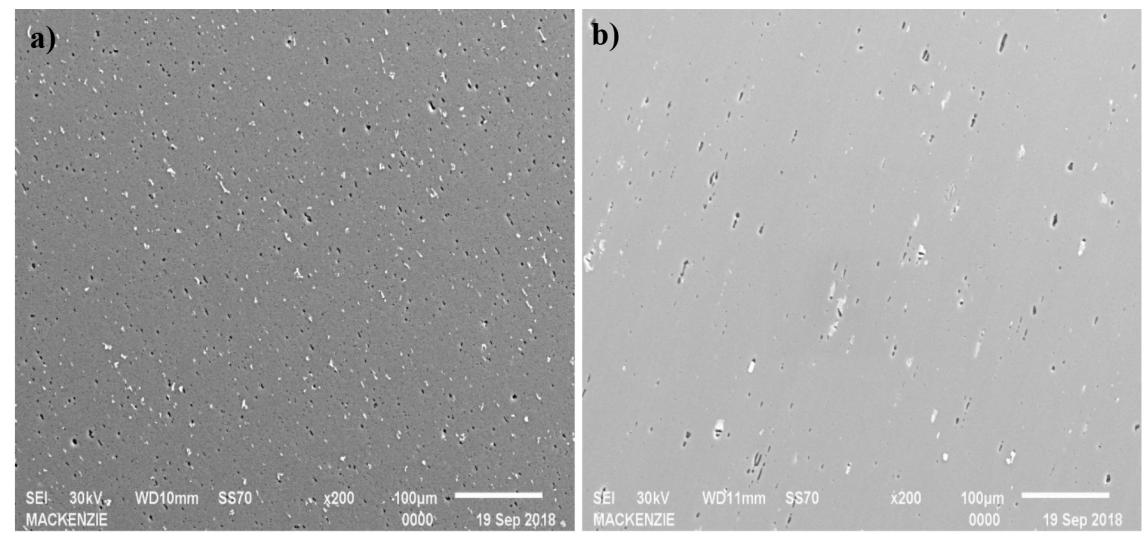

Figura 8 MEV com aumento de 200 x das amostras 3. a) Coroa nacional; b) coroa importada.

Fonte: Elaborada pelas autoras.

\subsection{Mediçóes de dureza}

Os valores de dureza Brinell e de microdureza Vickers foram obtidos na seção transversal de cada amostra. Foram feitas três indentaçóes em cada amostra e os resultados obtidos estão relacionados nas tabelas 5 e 6 . Para a escala Brinell, foi utilizada esfera de diâmetro $2,5 \mathrm{~mm}$ e carga de $31,35 \mathrm{~kg}$; para escala microdureza Vickers, a carga utilizada foi de $0,5 \mathrm{~g}$.

\section{TABELA 5}

Resultados de dureza Brinell.

\begin{tabular}{crrrrrr} 
Amostra & \multicolumn{3}{c}{ Coroa nacional } \\
\hline 1 & 89,77 & 89,77 & 89,77 & 164,19 & 164,19 & 151,44 \\
2 & 87,06 & 84,47 & 84,47 & 157,63 & 157,63 & 157,63 \\
3 & 98,68 & 87,06 & 87,06 & 157,63 & 151,44 & 157,63 \\
\hline
\end{tabular}

Fonte: Elaborada pelas autoras. 
TABELA 6

Resultados de microdureza Vickers.

\begin{tabular}{ccccccc} 
Amostra & \multicolumn{3}{c}{ Coroa nacional } & \multicolumn{3}{c|}{ Coroa importada } \\
\hline 1 & 85,40 & 90,30 & 78,80 & 164,70 & 166,90 & 166,50 \\
2 & 86,70 & 102,90 & 88,90 & 172,60 & 173,00 & 172,10 \\
3 & 86,40 & 86,10 & 87,40 & 177,40 & 179,90 & 175,90 \\
\hline
\end{tabular}

Fonte: Elaborada pelas autoras.

As diferenças observadas nos valores de dureza das coroas eram esperadas, haja vista a distinção das composiçôes químicas e morfologias dos grãos. $\mathrm{O}$ alto teor de elementos de liga, somado à estrutura de gráos com aspecto alongado da coroa importada, podem justificar o valor mais alto de dureza em comparaçáo à coroa nacional, que não apresentou teores significativos de elementos de liga que pudessem contribuir com um aumento de resistência mecânica.

\section{CONCLUSÓES}

As amostras deste trabalho foram analisadas quimicamente e seus aspectos metalúrgicos avaliados foram microestrutura e dureza. Em relação à análise química:

a) a coroa importada apresentou maior número de elementos de liga, com teores bastante significativos se comparados à coroa nacional, resultando em um material "mais carregado";

b) o zinco (bastante utilizado em peças sujeitas a elevado esforço mecânico), ao se apresentar em teor elevado na coroa de alumínio importada, justifica o comportamento de maior resistência ao desgaste. A maior resistência ao desgaste da coroa de alumínio importada foi relatada pelo doador das amostras aos autores deste estudo, e constatada pela maior vida útil da coroa de alumínio importada em relação à coroa de alumínio nacional, quando utilizadas nos carros de kart. Além disso, o teor de cobre é bastante discreto na coroa fabricada no Brasil, desfavorecendo a resistência mecânica, visto que esse elemento elevaria essa propriedade; 
c) a combinação dos elementos zinco, cobre e manganês proporciona ao material melhorias na resistência mecânica em relação ao desgaste. Por meio das técnicas utilizadas, foi possível observar que esse conjunto de elementos está presente na coroa de alumínio importada, podendo classificá-la como uma liga trabalhável da série 7000 .

Com relação à microestrutura:

a) na microscopia óptica, foi possível observar a estrutura de grãos e a distribuição das partículas de segundas fases. Os resultados apresentados pela coroa importada indicaram características de um material que sofreu conformação mecânica, devido à microestrutura formada por grãos de aspecto encruado e o alinhamento de partículas de segundas fases. As microestruturas das amostras da coroa nacional apresentaram grãos equiaxiais, o que pode indicar que o processo aplicado tenha sido de fundição. Dessa forma, a conformação mecânica pode ter sido um fator importante para explicar o diferente comportamento quanto ao desgaste entre as coroas;

b) por meio da MEV, pôde-se confirmar as diferenças encontradas na microscopia óptica, em relação à distribuição das partículas de segundas fases.

No que diz respeito à dureza, os resultados na escala Brinell e na escala microdureza Vickers foram discrepantes entre as amostras das coroas. Na coroa importada, os valores de dureza foram mais elevados. Esses resultados podem ser explicados pela estrutura originada da conformação mecânica e pelo alto teor de elementos de liga. Os baixos valores de dureza apresentados pela coroa nacional podem estar associados ao fato de ser um material menos "carregado" quimicamente em elementos que contribuam para a resistência mecânica.

\title{
CHARACTERIZATION OF IMPORTED AND NATIONAL ALUMINUM CASTING CROWN
}

\begin{abstract}
Among the alloys used in the automotive industry, aluminum is highlighted due to its lightness, good corrosion resistance, high ductility, and optimum environmental performance. The objective of this work was to study the different behavior regarding the wear of crowns in aluminum alloys of national and imported origin, used in kart cars. During the experimental stages, samples were characterized by Brinell hardness and micro Vickers, microstructural analysis by optical microscopy (OM) and by
\end{abstract}


scanning electron microscopy (SEM), and chemical composition analysis by X-ray energy dispersion spectroscopy (EDS), X-ray fluorescence, and atomic absorption. The samples of the imported crown presented higher hardness than the samples of the national crown, high zinc content, and microstructure formed by strain hardened grains / aligned second phase particles. The samples of the national crown presented lower levels of alloying elements, less hardness compared to the imported crown and grain structure that can be associated with the as cast condition.

Keywords: Aluminum alloy crowns. Kart. Grain structure. Hardness. Chemical composition.

\section{REFERÊNCIAS}

ASSOCIAÇÃO BRASILEIRA DO ALUMÍNIO - ABAL. Aplicaçōes do alumínio: automotivo e transportes - automóveis. São Paulo, 2021a. Disponível em: https://abal.org.br/aplicacoes/ automotivo-e-transportes/automoveis/. Acesso em: 7 fev. 2021.

ASSOCIAÇÃO BRASILEIRA DO ALUMÍNIO - ABAL. Aplicaçôes do aluminio: automotivo e transportes - caminhóes e implementos rodoviários. São Paulo, 2021b. Disponível em: https://abal.org.br/aplicacoes/automotivo-e-transportes/caminhoes-e-onibus/. Acesso em: 7 fev. 2021.

AFFONSO, L. O. M. Equipamentos mecânicos: análise de falhas e solução de problemas. Rio de Janeiro: Qualitymark, 2002.

ASSOCIAÇÃO BRASILEIRA DE NORMAS TÉCNICAS - ABNT. NBR ISO 209: Alumínio e suas ligas - composição química. 1. ed. Rio de Janeiro: ABNT, 2010.

CALLISTER JR., D. W. Ciência e Engenharia de Materiais: uma introduçáo. 8. ed. Rio de Janeiro: Gen, 2012.

MOHAMMADTAHERI, M. A New Metallographic Technique for Revealing Grain Boundaries in Aluminum Alloys. Metallography, Microstructure, and Analysis, v. 1, p. 224-226, 2012. Disponível em: https://link.springer.com/article/10.1007/s13632-012-0033-9. Acesso em: 8 out. 2018.

WONGTSCHOWSKI, F. Corrida pela tecnologia. Revista Aluminio, São Paulo, v. 8, n. 49, p. 16-18, out. 2016. 


\section{AGRADECIMENTOS}

Aos professores da Universidade Presbiteriana Mackenzie pela contribuição durante nossa graduação. Em especial, agradecemos ao doador das amostras, Prof. Dr. Jan Vatavuk, que nos incentivou e propôs este desafio, e ao Prof. Leonardo Calicchio, pela enorme colaboração à nossa formação como profissionais de Engenharia e por aceitar participar de nossa banca avaliadora.

\section{Contato}

Gisele Szilágyi

1133692@mackenzie.br

\section{Tramitação}

Recebido em março de 2019.

Aprovado em junho de 2021. 